\title{
The effects of hedgehog ligand neutralising antibody 5E1 in a mouse model of endometriosis
}

\author{
F. L. Cousins ${ }^{1,2^{*}}$ D , J. K. Farley ${ }^{1}$, R. Kerrigan ${ }^{1}$, S. Mukherjee ${ }^{1,2}$, S. Darzi ${ }^{1,2}$, C. E. Gargett ${ }^{1,2}$ and J. A. Deane $2^{2^{*}}$
}

\begin{abstract}
Objective: Endometriosis is a common and painful condition characterised by the formation of endometrial lesions within the peritoneal cavity. Previous studies have suggested a role for hedgehog signalling in the pathogenesis of endometriosis. We investigated the role of hedgehog signalling in the establishment of endometriosis lesions using $5 E 1$, a hedgehog ligand neutralising antibody, and a mouse model of endometriosis. To mimic the initiation of endometriosis by retrograde menstruation, which is believed to occur in humans, donor mice underwent an artificial menstruation protocol. Fragments of menstrual endometrium were injected into the peritoneal cavity of estrogen primed recipients. Recipients received twice weekly injections of 5E1 or an isotype matched control antibody for three weeks. Lesions were collected and analysed for markers of epithelium, proliferation and apoptosis by immunofluorescence microscopy.

Results: Treatment with 5E1 reduced the number of lesions found on the mesentery. No significant changes were found in the size of lesions, abundance of endometrial epithelial cells, proliferation or apoptosis.
\end{abstract}

Keywords: Endometrium, Endometriosis, Hedgehog signalling, Mouse model

\section{Introduction}

Endometriosis is a complex disorder of unknown aetiology, defined by the growth of endometrial fragments outside the uterine cavity. Endometriosis is thought to occur via the retrograde menstruation of endometrial fragments into the peritoneal cavity which then persist and form lesions on intra-peritoneal organs [1]. Retrograde menstruation occurs in $90 \%$ of menstruating females, yet only $10 \%$ go on to develop endometriosis, indicating that additional factors are involved [2]. Published data highlights that eutopic endometrial stromal cells from women with endometriosis exhibit increased adherence

\footnotetext{
*Correspondence: fiona.cousins@hudson.org.au; james.deane@monash.edu ${ }^{1}$ The Ritchie Centre, Hudson Institute of Medical Research, 27-31 Wright Street, Clayton, VIC, Australia

2 Department of Obstetrics and Gynaecology, School of Clinical Sciences At Monash Health, Monash University Faculty of Medicine, 246 Clayton Road, Clayton 3168, Australia
}

and proliferation in vitro $[3,4]$. It is likely that cell signalling and cell growth pathways of eutopic endometrial cells are altered in women with endometriosis. Current non-surgical treatments for endometriosis are largely oral contraceptives, to limit retrograde menstruation and growth of established lesions, or analgesics for pain. Non-hormonal therapeutics are desperately needed and targeting cell signalling pathways may reveal new avenues for drug design.

Hedgehog signalling is a developmental pathway that is activated in some endometrial cancers [5] and the endometrium of women with endometriosis [6]. Sonic hedgehog $(S H H)$ and its downstream signalling transcription factor GLI1 are upregulated in the eutopic endometrium of women with endometriosis in comparison to healthy controls [6]. Hedgehog signalling genes Shh, Gli1, Stil1 and Jag2 are also upregulated in the ectopic lesions of a mouse model of endometriosis featuring enhanced lesion

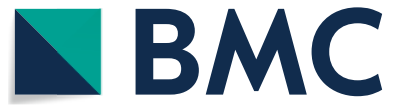

c) The Author(s) 2020. This article is licensed under a Creative Commons Attribution 4.0 International License, which permits use, sharing, adaptation, distribution and reproduction in any medium or format, as long as you give appropriate credit to the original author(s) and the source, provide a link to the Creative Commons licence, and indicate if changes were made. The images or other third party material in this article are included in the article's Creative Commons licence, unless indicated otherwise in a credit line to the material. If material is not included in the article's Creative Commons licence and your intended use is not permitted by statutory regulation or exceeds the permitted use, you will need to obtain permission directly from the copyright holder. To view a copy of this licence, visit http://creativeco mmons.org/licenses/by/4.0/. The Creative Commons Public Domain Dedication waiver (http://creativecommons.org/publicdomain/ zero/1.0/) applies to the data made available in this article, unless otherwise stated in a credit line to the data. 
formation [7]. Hedgehog signalling regulates cell proliferation, differentiation and stromal fibroblast maintenance in the endometrium via the FAK/ERK1/2 and PI3K/Akt signalling pathways [8]. Both of these pathways have been implicated in the pathogenesis of endometriosis [9], with prolonged phosphorylation of ERK in endometrial epithelial [10] and stromal cells [11] and endometriomas [12] and increased phosphorylated Akt in ovarian endometriomas [13]. HOXA10 is a developmental transcription factor that has been linked to endometriosis, and, like hedgehog signalling, is involved in progesterone induced endometrial differentiation [14]. This evidence suggests that hedgehog signalling contributes to the pathogenesis of endometriosis. Thus, hedgehog signalling may have value as a diagnostic marker for endometriosis and as a therapeutic target.

Highly specific antibodies are increasingly being used in therapeutic applications [15]. The 5E1 monoclonal antibody recognises mammalian hedgehog ligands and prevents hedgehog signal transduction via the Patched receptor. 5E1 is commonly used as a tool to block hedgehog signalling in mouse-based in vivo experiments [16, 17]. In the current study we investigated the potential of hedgehog blocking antibodies as a therapy for endometriosis by using $5 \mathrm{E} 1$ in a mouse model that closely mimics the human condition.

\section{Main Text}

Materials and methods

\section{Animal ethics}

All animals were held in the Monash Medical Centre Animal Facility and housed on a 12-h light/day cycle with access to normal chow and water ab libitum. Approval for all procedures described was obtained from Monash Medical Centre Animal Ethics Committee A.

\section{Mouse model of endometriosis}

C57BL/6J background mice 8-12 weeks age underwent the mouse model of endometriosis as published previously [18]. Briefly, donor mice were ovariectomised, then given sub-cutaneous injections of $\beta$-estradiol $(1 \mu \mathrm{g} / \mathrm{ml})$ on days 7-9. A progesterone secreting pellet was placed sub-cutaneously from days 13-19 (500 ng/day) in combination with $\beta$-estradiol sub-cutaneous injections from days $13-15$ (50 ng/ml). On day 15 the endometrium was artificial decidualised by injecting $20 \mu \mathrm{l}$ of oil into the uterine lumen. Progesterone support was removed on day 19 and $4 \mathrm{~h}$ later the menstrual-like endometrium was removed from the outer myometrium, minced into fragments approximately $1 \mathrm{~mm}^{3}$ and injected into ovariectomised estrogen primed ( $\beta$-estradiol secreting pellet, $100 \mathrm{ng} /$ day days 7-19) recipients (approximately 20 fragments, $200 \mathrm{mg}$ of tissue in $200 \mu \mathrm{l}$ of PBS). Lesions were allowed to develop over 21 days (days 19-40) before collection on day 40. During this 21-day period mice were randomly allocated to one of two groups and treated twice weekly with either $250 \mu \mathrm{g}$ of anti-SHH antibody $5 \mathrm{E} 1(\mathrm{n}=15, \mathrm{DSHB})$ or an isotype matched control antibody $(\mathrm{n}=18$, BioXCell, MOPC-21 IgG1) in $200 \mu \mathrm{l}$ of sterile PBS. The 5E1 dose administered was based on previous reports that used this antibody to block hedgehog signalling in mouse in vivo tumour models [19].

\section{Lesion collection and fixation}

Recipient mice were euthanised using rising concentrations of carbon dioxide and cervical dislocation. Upon dissection all body cavities were photographed, the number of lesions found recorded and their size measured. Lesions were carefully removed from peritoneal organs and immersed in 4\% w/v paraformaldehyde in PBS overnight at $4{ }^{\circ} \mathrm{C}$ and cryoprotected in $30 \% \mathrm{w} / \mathrm{v}$ sucrose in PBS overnight at $4{ }^{\circ} \mathrm{C}$. Tissues were frozen in optimal cutting temperature medium and cryo-sectioned at $8 \mu \mathrm{m}$ thick.

\section{Immunofluorescence analysis}

Unless otherwise stated all sections underwent the following staining protocol. Sections were permeabilised in 0.2\% Triton X-100 in PBS for 15 min, blocked in DAKO blocking solution for $1 \mathrm{~h}$ and then stained for hedgehog activation, (GLI1 Rabbit monoclonal Thermo MA5$3255310 \mu \mathrm{g} / \mathrm{ml}$ ), epithelial (EpCAM-PE rat anti mouse eBioscience 12-5791-81 $2 \mu \mathrm{g} / \mathrm{ml}$ ), proliferation (Ki67EF660 rat anti mouse eBioscience 50-5698-80 $2 \mu \mathrm{g} / \mathrm{ml}$ ) and apoptosis (Caspase 3 Rabbit polyclonal R\&D AF835 $5 \mu \mathrm{g} / \mathrm{ml}$ ) markers for $1 \mathrm{~h}$ at room temperature in $1 \%$ bovine serum albumin in PBS. For unconjugated primary antibodies, sections were incubated with secondary antibodies for $1 \mathrm{~h}$ at room temperature (Donkey anti rabbit Alexafluor 568 LifeTech A10042 $4 \mu \mathrm{g} / \mathrm{ml})$. Nuclei were counterstained with $5 \mu \mathrm{g} / \mathrm{ml}$ Hoescht 33258 in PBS for $3 \mathrm{~min}$. Images were captured on an Olympus FV1200 confocal microscope using a $20 \times$ objective lens and adjusted for brightness and contrast in a linear manner using FIJI software [20].

\section{Analysis of lesions}

Histological analysis Haematoxylin and eosin staining was performed as per standard protocols on the 15 th slide of each lesion ( 2 sections/slide $\times 8 \mu \mathrm{m} \times 15$ slides $=240 \mu \mathrm{m}$ deep). Lesion cross-sectional area was measured using FIIJ, using the trace outline and measure area tools.

Prior to the analysis of epithelial, proliferation and apoptosis markers, slides were blinded to reduce any bias during analysis. Markers were counted manually in FIJI. 
Total cell nuclei were calculated by counting the number of nuclei using the "threshold", "watershed" and "analyse particles" functions. A minimum of 6 lesions were analysed per treatment group. A minimum of 3 fields of view per section were imaged and the average percentage of positive cell types in the total cell population was calculated for each lesion. Results were then unblinded and each lesion was then plotted as a single data point.

\section{Statistical analysis}

Group sizes were determined using G*Power software. For lesion number, we assumed an observed effect size of 0.5 , alpha of 0.05 and Power of 0.8 , the total sample size required was 26 . For changes in lesion characteristics we assumed an effect size of 0.65 , alpha of 0.05 and Power of 0.8 , the total sample size required was 13 .

All statistical analyses were performed in Graphpad Prism 8.0. Raw data was subjected to D'Agostino-Pearson normality testing prior to statistical analyses. Non-parametric analysis was performed when one of the sets of data failed to pass normality testing. All lesion analyses were subjected to unpaired, two-tailed Mann-Whitney testing. Significance was accepted where $\mathrm{P} \leq 0.05$ and data represented graphically as individual data points and median.

\section{Results and discussion}

\section{The location and incidence of lesions}

Lesions were found at various locations in the isotype control and anti-SHH treated group (Fig. 1a). The occurrence of lesions, indicative of endometriosis, was $100 \%$ in the isotype control treated group and $80 \%$ in anti-SHH treated group $(\mathrm{p}=0.08)$ (Fig. 1b). In line with other reports using this model, irrespective of treatment, most lesions were detected on the mesentery $(83 \%$ in the isotype control group, $67 \%$ in the $5 \mathrm{E} 1$ group) [18]. Lesions were also found on the body wall, on the external surface of the uterus and on the digestive tract (includes stomach, small intestine, large intestine) (Fig. 1c). There was a significant decrease in the number of lesions per recipient detected on the mesentery after anti-SHH treatment compared to isotype control $(\mathrm{p}<0.01)$ (Fig. 1d). This decrease was not observed for other locations but these lesions were infrequent and the dataset was small (Fig. 1d). Given the decrease in the number of mesenteric lesions we assessed their lesion area independent of other lesions but found that this sub-group did not display any difference in area ( $\mathrm{p}=0.0932$, data not shown).
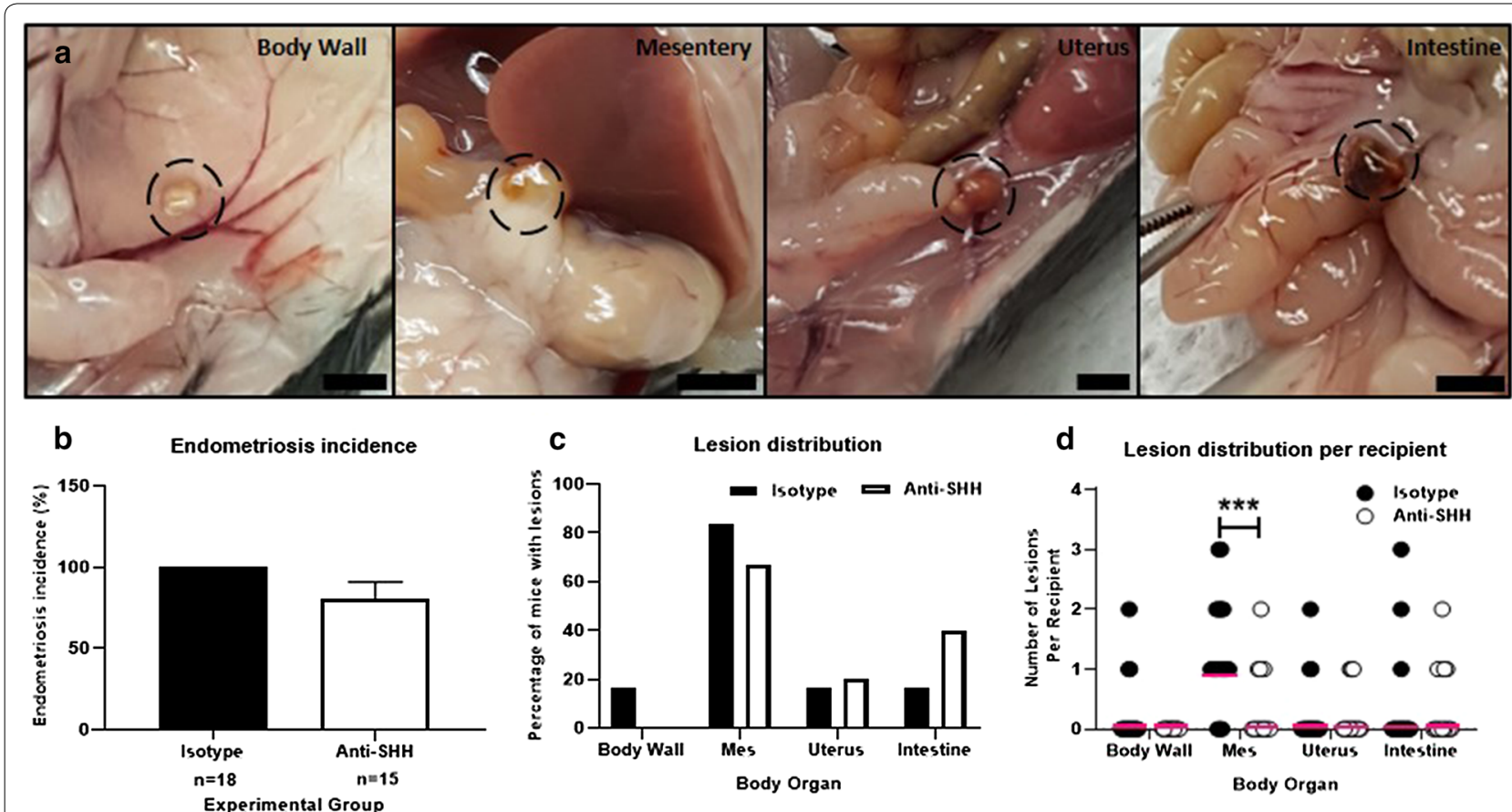

Fig. 1 Endometriosis incidence and lesion location following treatment with anti-SHH antibody. a Lesions (dashed circles) were identified on different organs within the body cavity, including the body wall, mesentery, uterus and intestine. Scale bars $3 \mathrm{~mm}$. b Endometriosis incidence was calculated as the percentage of mice with detectable lesions at three weeks, isotype control $n=18$, anti-SHH $n=15$. Data displayed as mean \pm SEM. $\mathbf{c}$ The percentage of mice with lesions at different sites. $\mathbf{d}$ The number of lesions/recipient at each site. Isotype $v$ anti-SHH for each site was tested using an unpaired, two-tailed Mann-Whitney test. ${ }^{* * *} p<0.001$. Pink line denotes median 


\section{Gli1 expression as an indicator of hedgehog activation}

Gli1 was examined by immunostaining to detect hedgehog activation in collected lesions. Gli1 was readily detected in mouse brain, a known site of hedgehog signalling [21]. Very weak to no signal was detected in isotype and anti-SHH lesions from the endometriosis model (Fig. 2a, representative of 3 animals). This suggests that endometriotic lesions do not have the high levels of hedgehog activation found in some tumours $[5,22-24]$. GLI1 expression is increased in the endometrium of women with endometriosis in comparison to healthy controls [6], and in ovarian endometriomas [25] but expression in human lesions at other sites is yet to be assessed. Our mouse model does not address ovarian endometriomas due to recipients being ovariectomised, therefore we cannot comment on whether the ovarian location would result in differing GLI1 expression. Furthermore, the human study used a polyclonal antibody, whereas the antibody used in our mouse studies was a monoclonal (clone JF09-08) which may account for discrepancy in results.

\section{Lesion characteristics}

Lesion establishment and survival relies on cross-talk between epithelial cells and the surrounding stroma [26]. Lesions were investigated for expression of the epithelial cell marker EpCAM, proliferation marker Ki67 and apoptosis marker Caspase 3 (Fig. 2b and c). Variable expression of EpCAM was identified in the isotype control group. Fifty-eight percent of isotype lesions (7 of 12) had detectable EpCAM expression ranging from $0.17-26 \%$

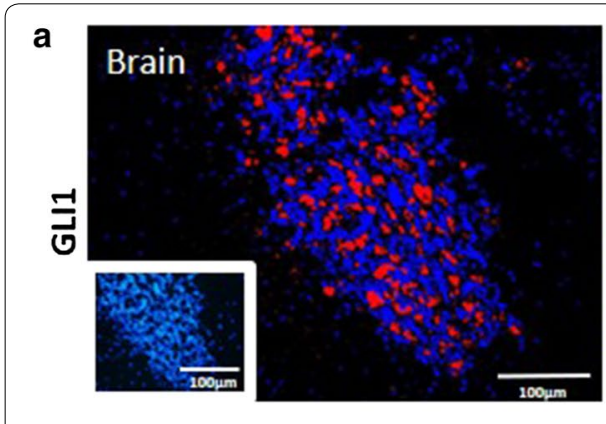

b
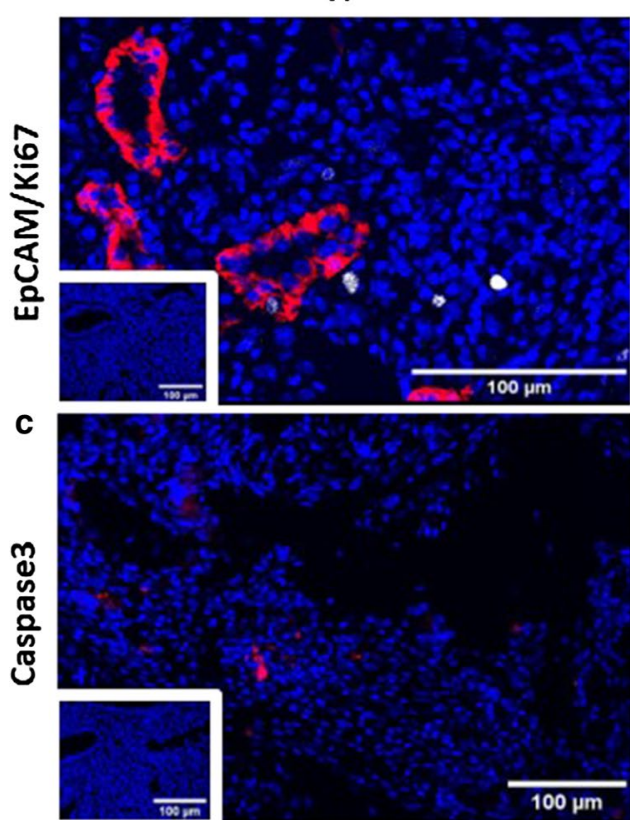
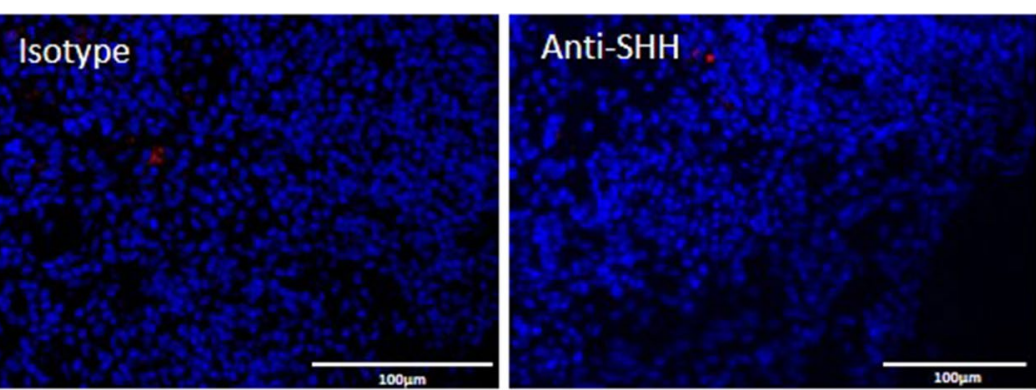

Anti-SHH
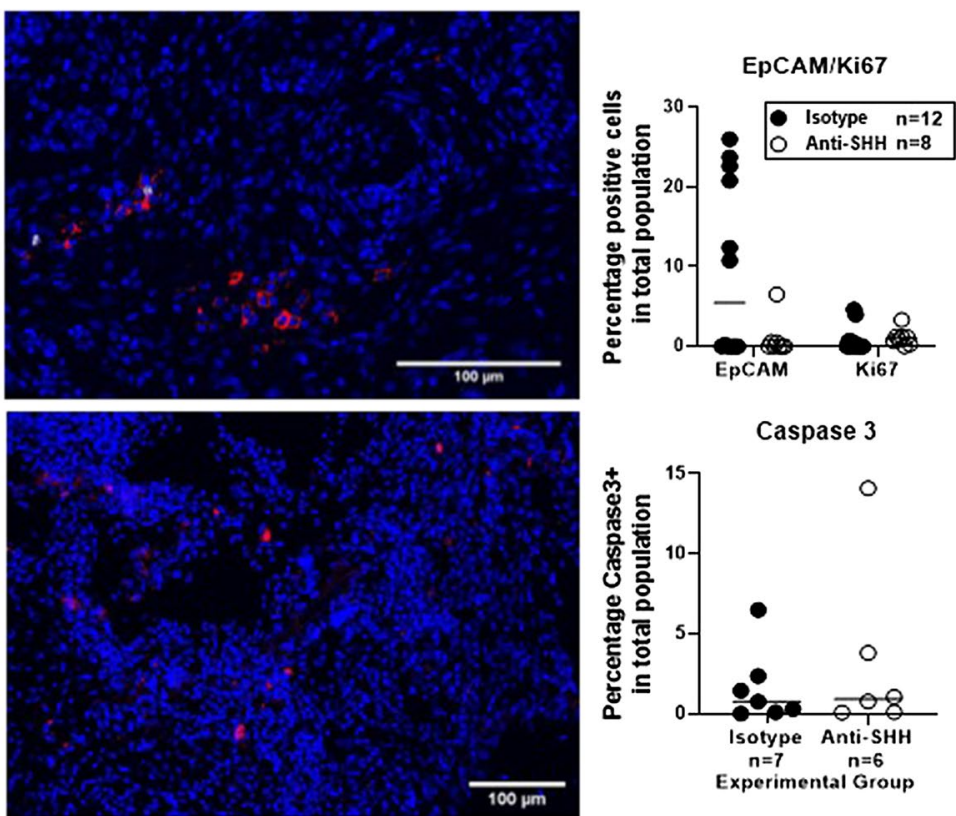

Caspase 3

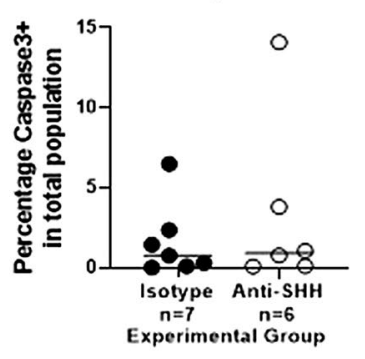

Fig. 2 Expression of SHH pathway and cell identity markers did not change with anti-SHH treatment. a Gli1 expression (red) was detected in the mouse brain but was barely detected in lesions from either group. Inset rabbit IgG1 isotype control. b Dual immunofluorescence for EpCAM (red) and Ki67 (white), insert isotype control. c Immunofluorescence for Caspase 3 (red), insert isotype control. B+ C quantification; EpCAM, Ki67 and Caspase 3 expressed as a percentage of total cell population, isotype control (black circles) and anti-Shh (white circles). Data analysed by an unpaired, two-tailed Mann-Whitney test 
positive cells in the total population. In the anti-SHH group, only $37.5 \%$ of lesions had detectable expression of EpCAM (3 of 8 lesions), only 1 lesion had a detectable level over $1 \%$ positive in the total cell population. Despite no significant decrease in EpCAM expression, the observed downward trend is in line with another report where a hedgehog inhibitor decreased endometrial epithelial cell proliferation in vitro [27].

No significant differences were identified between isotype control and anti-SHH groups for Ki67 and Caspase 3 (Fig. 2b and c), which suggests 5E1 has no direct effect on overall proliferation or apoptosis of endometriotic lesions.

\section{Conclusions}

Differences in hedgehog pathway activation have been detected in women with endometriosis and in mouse models of endometriosis $[6,7,28]$. This study aimed to see whether the hedgehog neutralising antibody 5E1 would prevent lesion establishment and progression in a mouse model of endometriosis. Significantly fewer lesions were found on the mesentery of animals treated twice weekly with 5E1. However, no significant differences were observed in the size and morphology of the lesions that formed. These data suggest that hedgehog signalling is not integral to lesion progression, but may play a role in the survival of menstrual fragments in the peritoneal cavity and lesion initiation.

\section{Limitations}

No effect of anti-SHH treatment was observed at other sites within the peritoneal cavity, however the number of lesions obtained from these sites was small $(n=4-6$ lesions) meaning it is not possible to draw clear conclusions. It is difficult to determine the mechanism by which mesenteric lesions are reduced from the data obtained.

\section{Abbreviations}

5E1: Sonic hedgehog neutralising monoclonal antibody, Clone 5E1; EpCAM: Epithelial cell adhesion molecule; $\mathrm{SHH}$ : Sonic hedgehog.

\section{Acknowledgements \\ We would like to acknowledge the support of the Monash Health Transla- tional Precinct's Research Platforms Monash Micro-Imaging and Monash Histology and animal technicians for animal husbandry and care.}

\section{Authors' contributions}

FLC, CEG and JAD designed the study. FLC, CEG and JAD obtained funding. FLC, SM, SD and JAD collected data. FLC, JKF, RK and JAD analysed data. FLC and JAD wrote the manuscript. All authors read and approved the final manuscript.

\section{Funding}

This study was supported by the Victorian Government's Operational Infrastructure fund and a Ferring Pharmaceuticals Innovation grant awarded to JA
Deane, CE Gargett and FL Cousins. Ferring Pharmaceuticals had no input into design, collection or interpretation of data.

\section{Availability of data and materials}

All relevant data generated in this study is presented in the manuscript.

\section{Ethics approval and consent to participate}

All mouse procedures were performed under approval MMCA2016-57 from Monash Medical Centre Animal Ethics Committee A.

\section{Consent for publication}

Not Applicable.

\section{Competing interests}

The authors declare they have no competing interests.

Received: 23 July 2020 Accepted: 20 September 2020

Published online: 25 September 2020

\section{References}

1. Sampson JA. Metastatic or Embolic Endometriosis, due to the Menstrual Dissemination of Endometrial Tissue into the Venous Circulation. Am J Pathol. 1927;3(2):93-110.

2. Giudice LC, Kao LC. Endometriosis. Lancet. 2004;364(9447):1789-99.

3. Beste MT, PfaffleDoyle N, Prentice EA, Morris SN, Lauffenburger DA, Isaacson KB, et al. Molecular Network Analysis of Endometriosis Reveals a Role for c-Jun-Regulated Macrophage Activation. Sci Transl Med. 2014;6(222):222ra16.

4. Klemmt PAB, Carver JG, Koninckx P, McVeigh EJ, Mardon HJ. Endometrial cells from women with endometriosis have increased adhesion and proliferative capacity in response to extracellular matrix components: towards a mechanistic model for endometriosis progression. Hum Reprod. 2007:22(12):3139-47.

5. Feng Y-Z, Shiozawa T, Miyamoto T, Kashima H, Kurai M, Suzuki A, et al. Overexpression of hedgehog signaling molecules and its involvement in the proliferation of endometrial carcinoma cells. Clin Cancer Res. 2007;13(5):1389-98.

6. He Y, Guo Q, Cheng Y, Qu Y, Sun L, Kong C, et al. Abnormal activation of the sonic hedgehog signaling pathway in endometriosis and its diagnostic potency. Fertil Steril. 2018;110(1):128-136.e2.

7. Heard ME, Simmons CD, Simmen FA, Simmen RCM. Krüppel-like factor 9 deficiency in uterine endometrial cells promotes ectopic lesion establishment associated with activated notch and hedgehog signaling in a mouse model of endometriosis. Endocrinology. 2014;155(4):1532-46.

8. Park SR, Kim SR, Park CH, Lim S, Ha SY, Hong IS, et al. Sonic hedgehog, a novel endogenous damage signal, activates multiple beneficial functions of human endometrial stem cells. Mol Ther. 2020;28(2):452-65.

9. McKinnon BD, Kocbek V, Nirgianakis K, Bersinger NA, Mueller MD. Kinase signalling pathways in endometriosis: potential targets for non-hormonal therapeutics. Hum Reprod Update. 2016;22(3):382-403.

10. Yotova IY, Quan P, Leditznig N, Beer U, Wenzl R, Tschugguel W. Abnormal activation of Ras/Raf/MAPK and RhoA/ROCKII signalling pathways in eutopic endometrial stromal cells of patients with endometriosis. Hum Reprod. 2011;26(4):885-97.

11. Velarde MC, Aghajanova L, Nezhat CR, Giudice LC. Increased mitogenactivated protein kinase kinase/extracellularly regulated kinase activity in human endometrial stromal fibroblasts of women with endometriosis reduces $3^{\prime}, 5^{\prime}$-cyclic adenosine $5^{\prime}$-monophosphate inhibition of cyclin D1. Endocrinology. 2009;150(10):4701-12.

12. Ngô C, Nicco C, Leconte M, Chéreau C, Arkwright S, Vacher-Lavenu MC, et al. Protein kinase inhibitors can control the progression of endometriosis in vitro and in vivo. J Pathol. 2010;222(2):148-57.

13. Cinar O, Seval Y, Uz YH, Cakmak H, Ulukus M, Kayisli UA, et al. Differential regulation of Akt phosphorylation in endometriosis. Reprod Biomed Online. 2009;19(6):864-71.

14. Zanatta A, Rocha AM, Carvalho FM, Pereira RMA, Taylor HS, Motta ELA et al. The role of the Hoxa10/HOXA10 gene in the etiology of endometriosis and its related infertility: A review. J Assist Reprod Genet. 2010;27(12):701-10 
15. Dimitrov JD. Harnessing the therapeutic potential of 'Rogue' antibodies. Trends Pharmacol Sci. 2020;41:409-17.

16. Beachy PA, Hymowitz SG, Lazarus RA, Leahy DJ, Siebold C. Interactions between hedgehog proteins and their binding partners come into view. Genes Dev. 2010;24:2001-122.

17. Cucchi D, Occhione MA, Gulino A, De Smaele E. Hedgehog signaling pathway and its targets for treatment in basal cell carcinoma. J Exp Pharmacol. 2012;4:173-85.

18. Greaves E, Cousins FL, Murray A, Esnal-Zufiaurre A, Fassbender A, Horne AW, et al. A novel mouse model of endometriosis mimics human phenotype and reveals insights into the inflammatory contribution of shed endometrium. Am J Pathol. 2014;184(7):1930-9.

19. Bailey JM, Mohr AM, Hollingsworth MA. Sonic hedgehog paracrine signaling regulates metastasis and lymphangiogenesis in pancreatic cancer. Oncogene. 2009;28:3513.

20. Schindelin J, Arganda-Carreras I, Frise E, Kaynig V, Longair M, Pietzsch T, et al. Fiji: an open-source platform for biological-image analysis. Nat Methods. 2012;9(7):676-82.

21. Dahmane N, Sánchez P, Gitton Y, Palma V, Sun T, Beyna M, et al. The Sonic hedgehog-Gli pathway regulates dorsal brain growth and tumorigenesis. Development. 2001;128(24):5201-12.

22. Thayer SP, Di Magliano MP, Heiser PW, Nielsen CM, Roberts DJ, Lauwers GY, et al. Hedgehog is an early and late mediator of pancreatic cancer tumorigenesis. Nature. 2003;425(6960):851-6.

23. Ruiz I, Altaba A, Stecca B, Sánchez P. Hedgehog-Gli signaling in brain tumors: Stem cells and paradevelopmental programs in cancer. Cancer Lett. 2004;204(2):145-57.
24. Wang LH, La CY, Hua XY, Shin YK, Song YJ, Youn SJ, et al. Increased expression of sonic hedgehog and altered methylation of its promoter region in gastric cancer and its related lesions. Mod Pathol. 2006;19(5):675-83.

25. Liu H, Zhang W, Wang L, Zhang Z, Xiong W, Zhang L, et al. GLI1 is increased in ovarian endometriosis and regulates migration, invasion and proliferation of human endometrial stromal cells in endometriosis. Ann Transl Med. 2019;7(22):663-663.

26. Hull ML, Escareno CR, Godsland JM, Doig JR, Johnson CM, Phillips SC, et al. Endometrial-peritoneal interactions during endometriotic lesion establishment. Am J Pathol. 2008;173(3):700-15.

27. Nakajima T, Iguchi T, Sato T. Hedgehog signaling plays roles in epithelial cell proliferation in neonatal mouse uterus and vagina. Cell Tissue Res. 2012;348(1):239-47.

28. Heard ME, Velarde MC, Giudice LC, Simmen FA, Simmen RCM. Krüppellike factor 13 deficiency in uterine endometrial cells contributes to defective steroid hormone receptor signaling but not lesion establishment in a mouse model of endometriosis. Biol Reprod. 2015;92(6):140.

\section{Publisher's Note}

Springer Nature remains neutral with regard to jurisdictional claims in published maps and institutional affiliations.
Ready to submit your research? Choose BMC and benefit from:

- fast, convenient online submission

- thorough peer review by experienced researchers in your field

- rapid publication on acceptance

- support for research data, including large and complex data types

- gold Open Access which fosters wider collaboration and increased citations

- maximum visibility for your research: over $100 \mathrm{M}$ website views per year

At BMC, research is always in progress.

Learn more biomedcentral.com/submissions 